\title{
Fortalecer los músculos para mejorar la raza. Discursos eugenésicos sobre educación del cuerpo en revistas pedagógicas de Argentina y Brasil (1920-1940)
}

\author{
Strengthen muscles to improve the race. Eugenic discourses about body education in pedagogical journals of \\ Argentina and Brazil (1920-1940)
}

\author{
Eduardo Lautaro Galak \\ CONICET/Instituto de Investigaciones en Humanidades y Ciencias Sociales. \\ Universidad Nacional de La Plata, Argentina \\ eduardogalak@gmail.com
}

\section{Resumen:}

En esta investigación se analizan discursos sobre educación eugenésica de los cuerpos en Argentina y en Brasil entre las décadas de 1920 y 1940. Con una metodología histórico-hermenéutica se estudiaron significaciones publicadas en la prensa pedagógica de estos países, especialmente aquella "oficial" de la provincia de Buenos Aires y del estado de Minas Gerais, a través de la Revista de Educación y la Revista do Ensino respectivamente. Sin pretender universalizar, se parte de la hipótesis de que en ambos márgenes de la frontera argentino-brasilera existieron políticas públicas sobre los cuerpos, las cuales muestran particularidades y recurrencias en los usos de sentidos eugenésicos como retóricas legitimadoras. Ello permite interpelar el uso de la cultura física como dispositivo para transmitir una higiene moral y la fórmula que la ubica como vehículo para mejorar la raza y progreso de la patria, para así resignificar el lugar del cuerpo como objeto de políticas públicas.

Palabras clave: Cultura física, Eugenesia, Políticas del cuerpo, Argentina, Brasil.

\begin{abstract}
:
This research analyzes eugenic discourses about corporal education in Argentina and Brazil between 1920 and 1940. With a historical-hermeneutic methodology, it is studied meanings published in pedagogical "official" journals of these countries, focusing in the Revista de Educación (Buenos Aires province) and Revista do Ensino (Minas Gerais estate). This investigation bases on the hypothesis that on both sides of the Argentine-Brazilian border there were public policies on bodies, which show particularities and recurrences in the uses of eugenic senses as legitimate rhetoric. In order to resignify the place of the body as an object of public policies, this research allows us to question the uses of physical culture as a mechanism to transmit a moral hygiene and the axiom that perform it as a vehicle to improve the race and progress of the country.
\end{abstract}

KeYwords: Physical culture, Eugenics, Body politics, Argentina, Brazil.

\section{ForTALECER LOS MÚSCULOS PARA MEJORAR LA RAZA}

Observar los puentes que se tejen entre dos contextos disímiles pero emparentables como el argentino y el brasilero permite comprender la difusión de ideas, la interpretación de las mismas y la búsqueda por su reproducción. En efecto, en el juego entre las particularidades y recurrencias de los procesos políticos ocurridos en Brasil y en Argentina se vislumbran características epistémicas e idiosincrásicas, las cuales habilitan a pensar estos contextos por separado y en conjunto.

Con este telón de fondo se percibe por qué estos sentidos se ven claramente en la prensa analizada, por las múltiples referencias cruzadas de hechos, palabras, prácticas y autores: tanto en la Revista de Educación, estudiada entre 1922 y 1940, como en la Revista do Ensino, indagada desde su fundación en 1925 hasta el final del recorte temporal propuesto, puede observarse un uso particular de las retóricas pedagógicas que propiciaban fortalecer los cuerpos para mejorar la raza ${ }^{1}$. Además de haber sido el efecto de políticas públicas 
de difusión de los procesos de escolarización, ambas publicaciones funcionaron como la "voz oficial" de dos de los estados más importantes de cada país, el de Buenos Aires y el de Minas Gerais respectivamente. Se interpreta un carácter de "oficialidad" porque cada palabra impresa en estas revistas estaba investida de cierta condición de legitimidad, incluso con el eclecticismo que las caracterizó. Dicho de otro modo, el análisis propuesto resignifica el concepto de retórica de lo oficial, que desarrolla Pierre Bourdieu (2014). Este autor entiende que los estados a través de sus diversos estamentos desplegaron una (con)fusión de lo estrictamente oficial-estatal con sentidos que resultan performativamente oficializados por la legitimación de su mandato y por la efectividad de su operación. Como parte de ese mismo dispositivo se constituye un entramado que hace de lo "oficial" un sinónimo de lo legítimo y lo universal.

De allí que los discursos indagados no puedan ser pensados como aislados de cierto clima de época contextual: pensar las políticas estatales -como en este caso mediante las revistas educativas- supone reflexionar acerca de lo oficial y de lo público, y, por ende, sobre aquello que porta sentidos de universalidad. De esta manera, aun cuando se imprimieron una heterogeneidad de significaciones, se parte de concebir que las notas editadas por la Revista de Educación y la Revista do Ensino representan aquellos posicionamientos legitimados y reproducidos dentro del campo pedagógico argentino y brasilero entre 1920 y 1940. Precisamente, esta cuestión motiva este artículo: ambas revistas reflejan un entramado de cosmovisiones generales que permiten reconstruir sentidos de "argentinidad" y la brasilidade de una época, especialmente aquellas ligadas a la transmisión escolarizada de prácticas corporales. En efecto, a partir de la concepción de que los procesos de escolarización suponen el principal mecanismo para la reproducción política (Pineau, Dussel y Carusso, 2001), se propone analizar las “tonalidades" de la voz oficial con el objeto de comprender no sólo las políticas educativas respecto de la cultura física en los contextos y períodos estudiados, sino también entender cierto sentido general de la política de formación de ciudadanos. En otras palabras, el objetivo de la presente indagación es interpelar aquellos discursos publicados por la Revista de Educación y la Revista do Ensino acerca de la transmisión de prácticas corporales y su relación con las retóricas sobre mejoramiento de la raza, y observar cómo se articularon, a través de las páginas pedagógicas, sentidos científicos higiénicoeugenésicos con sentidos educativos a fin de instaurar una moral colectiva que argumentara la realización de actividades físicas como sinónimo de progreso (de la patria). Para ello se investiga particularmente sobre significaciones y usos gubernamentales que tomaron a las prácticas corporales como su objeto: los argumentos de la afirmación que supone "hacer para perfeccionar la patria, fortalecer los músculos para mejorar la raza" 2 .

Aún con las vicisitudes macropolíticas y microcontextuales, el período entre 1920 y 1940 resultó internacionalmente importante para configurar una serie de signos que condicionan la educación de los cuerpos hasta la actualidad. Por sólo nombrar un par de ejemplos que son analizados, la común utilización del método gimnástico francés propuesto por Georges Hébert, con similares sentidos en ambos márgenes de la frontera y en las publicaciones pedagógicas mencionadas, demuestra que, a pesar de querer conformar una identidad en oposición a lo que ocurría fuera del país, existen similitudes argumentales transnacionales. De igual modo, la utilización del eclecticismo como estrategia editorial refleja que la norma era hacer para mejorar y perfeccionar, sin especificar bien en qué consistía lo normal. Estas cuestiones son claramente una muestra de las vicisitudes políticas, ideológicas, económicas y socioculturales que se produjeron en el período de entreguerras: en este caso, la reconfiguración de discursos que se produce en la década de 1930 en Argentina con el primer gobierno de facto, y en Brasil con el pasaje de la Republica Velha al Estado Novo en Brasil no dejaron de hacer convivir publicaciones de sentidos heterogéneos pero con tono homogeneizador, incluso con las respectivas tendencias autoritarias filototalitaristas. Como una suerte de punto bisagra de la historia política de ambos países, tanto en Argentina con la presidencia de José Félix Uriburu, que dio inicio a la denominada Década Infame, como en Brasil con el mandato de Getúlio Vargas, que instauró el Estado Novo, se produjeron en 1930 golpes de Estado cívico-militares que establecieron gobiernos de facto comandados por juntas militares, y que fundaron un segundo cuarto del siglo XX signado por la inestabilidad democrática y el afianzamiento de sentidos conservadores ${ }^{3}$. 
Por último, resulta preciso explicitar que, aun cuando estas líneas introductorias afirmativas tiendan a mostrar cierta coherencia en los discursos, lo cierto es que existen sobradas muestras en los documentos de las múltiples tensiones que atravesaron los sentidos "argentinos" y "brasileros" de educación eugenésica de los cuerpos entre las décadas de 1920 y 1930. De igual modo, si bien se refiere a sentidos de construcción de la argentinidad y de la brasilidade, en rigor de verdad las políticas educativas centralizadas fueron por momentos más una retórica que efectivamente una realidad. A pesar de que los discursos de la época refieren a sistemas educativos unificados, las experiencias en cada contexto fueron en realidad disímiles: en lo que respecta a Brasil, hasta la constitución nacional de 1932, e incluso posteriormente, pervivieron formas descentralizadas que priorizaban lo estadual antes que la unión federal (Veiga y Fonseca, 2003; Veiga, 2007), en tanto que para el caso de Argentina, por las vicisitudes macropolíticas, comenzaba a haber una fuerte disputa entre el Estado nacional y el sistema escolar bonaerense, cuestión que durante la gobernación de Manuel Fresco (1936-1940) queda en evidencia con la reforma educativa (Bisso, 2011). Sin embargo, por la pretensión de mostrar los sentidos oficiales y legitimados que a cada lado de la frontera se desarrollaron, se prioriza el análisis de los discursos dominantes por sobre las disputas que en cada contexto ocurrieron.

Por todo lo expuesto, puede comprenderse por qué para abordar esta problemática el esfuerzo epistemometodológico estuvo centrado en observar en publicaciones periódicas oficiales especializadas en educación aquellos discursos que específicamente refirieron a un modo de gobernar los cuerpos con el objetivo de fomentar una formación del carácter acorde a conductas reconocidas por la sociedad como "racialmente deseables". Para ello se definieron una serie de pautas metodológicas con el objeto de establecer qué notas pedagógicas conformarían el corpus documental de la presente indagación.

La primera consistió en observar las continuidades y rupturas (editoriales) de los materiales empíricos analizados en dos sentidos articulados. Por un lado, a través de un recorte temporal que abarcara sólo los artículos impresos en las décadas de 1920 y 1930: cabe la aclaración de que en el caso de la Revista de Educación el estudio abarcó desde 1922, lo que está justificado en el hecho de que ese año asumió como gobernador provincial José Luís Cantilo, y con ello se produjeron importantes cambios en materia de cultura física (Galak, 2015b). En cambio, la Revista do Ensino se analiza desde 1925, año de su refundación modernizadora (Vago, 2004; 2006). En este registro, el recorte temporal se sustenta en que ambas revistas comenzaron a inicios de la década de 1920 un proceso de refundación editorial que se manifiesta claramente en los discursos sobre educación de los cuerpos, lo cual se encuentra en línea con la puesta en boga de las retóricas que indican que ejercitarse produce un potencial mejoramiento de la raza y beneficio de la patria. Por otro lado, el recorte contextual se sustenta en el análisis de las publicaciones educativas oficiales de la provincia de Buenos Aires (Argentina) y del estado de Minas Gerais (Brasil). Esto es, se trata de reconstruir la historia de la pedagogización de los cuerpos a través de lo publicado en la Revista de Educación y en la Revista do Ensino procurando observar la educación bonaerense y mineira en particular, pero fundamentalmente los regímenes de argentinidad y de brasilidade que estos dispositivos ponían en circulación ${ }^{4}$. Esto significa que se parte de las palabras impresas para pensar la educación de los cuerpos bonaerenses y mineiros y no al revés, lo cual supone el ejercicio de reconstruir los trazos de procesos pasados condicionados por políticas gubernamentales propias de revistas estatales, y surcados por lógicas editoriales que enfatizan u omiten prácticas, saberes y discursos.

La segunda pauta metodológica está dada por la previa selección de una serie de palabras claves atinentes a la educación eugenésica del cuerpo: además de observar las notas que explícitamente contenían sentidos sobre eugenesia o raza, se establecieron categorías analíticas sobre noticias o reglamentaciones publicadas que procuraban transmitir sentidos sobre la higiene o la medicalización de la vida, sobre el movimiento a través de prácticas corporales (deportes, gimnasias, juegos), o a través de iniciativas gubernamentales al respecto (colonias de vacaciones, plazas de ejercicios físicos, excursiones), entre otras. En todos estos casos la intención de fondo consistía en comprender cuáles eran los sentidos políticos que justificaban la necesidad de que el Estado se hiciera cargo de la cultura física (en general amparado en criterios "superiores", como la patria, la salud, valores morales o incluso espirituales). 
Por último, como tercera pauta se estableció que los artículos impresos debían tener como intencionalidad la trascendencia de sus sentidos: más allá de la importancia de su lectura, su publicación se orientaba también a la reproducción de los postulados enunciados. De allí que se hayan analizado aquellos textos referidos a la educación del cuerpo que tuvieron por pretensión repercutir directamente sobre la profesionalidad especialmente en Educación Física-, a partir de la idea de que de esa manera se garantizaba, por lo menos parcial y localmente, que esas propuestas trascendieran su contexto de producción.

Estas opciones epistemometodológicas se justifican en el hecho de que se parte de pensar la educación de los cuerpos para -con ese trasfondo de análisis- reflexionar sobre el movimiento eugenésico, y con ello desplegar el giro sobrerreflexivo que permita interpelar los sentidos asociados tanto a la disciplina escolar Educación Física como a la cultura física en tanto dimensión social. En síntesis, el posicionamiento epistémico que explica estas consideraciones metodológicas se argumenta en la búsqueda por comprender las redes políticas y conceptuales tejidas, es decir, las estrategias de comunicación, divulgación y repetición que se utilizaron para la reproducción de prácticas, saberes y discursos.

\section{EDUCACIÓN DE LOS CUERPOS, SALUBRIDAD PÚBLICA, PATRIOTISMO Y EUGENESIA}

La influencia de los discursos eugenésicos en los dominios del campo de la educación de los cuerpos argentina y brasilera es significativa ${ }^{5}$. Particularmente, el período comprendido entre las décadas de 1920 y 1940 está marcado por una serie de reconfiguraciones acerca de cómo educar los cuerpos, pero fundamentalmente por qué y para qué. Históricamente entendido como secundario o complementario (Galak, 2009), el cuerpo se constituye desde el segundo cuarto del siglo XX en eje central explícito de políticas y blanco de intervención, y su escolarización fue uno de los vehículos predilectos para tal fin. En esta dirección, los discursos sobre la cultura física resultaron un método de transmisión de sentidos diversos, principalmente orientados como dispositivos para masificar y popularizar prácticas y discursos sobre salubridad y patriotismo, en su mayoría producto de políticas gubernamentales con tintes chauvinistas. Justamente esas dos claves de lectura son las que motivan la reflexión sobre la educación del cuerpo como objeto de las políticas públicas transmitidas a través de los procesos de escolarización.

Por un lado, los discursos enfocados explícitamente en la salubridad exponen la retórica justificadora de las campañas públicas, las cuales se vuelven de significativa importancia para el objeto de estudio de la presente investigación, ya que incorporan a la cultura física en general y a la Educación Física en particular como vehículo de transmisión de hábitos de higiene y sanidad (Kinoshita, Pimenta Rocha y Aisenstein, 2015; Galak, 2016), además de mover definitivamente el eje de lo individual a lo colectivo y de lo privado a lo público, hechos que constituyen movimientos típicamente modernos (Foucault, 1996; Espósito, 2007). Esto puede argumentarse en términos de un cierto sentido occidental "relativamente universal" de sumisión del cuerpo individual a prácticas, saberes y discursos colectivos. Esta cuestión se debe fundamentalmente a que en las primeras décadas del siglo XX ya se encontraba afianzada la centralización de los EstadosNación, lo que a la vez se asocia con la concepción de que la fortaleza de los cuerpos no está solamente condicionada por la fuerza de los músculos, sino, también, que es efecto de la representación social del vigor del conjunto que forma la patria. De modo análogo, también las razones para las políticas de salud corrieron el eje de lo individual a lo colectivo a través de las campañas de salubridad pública, a partir de resignificar sentidos asociados a la educación y control higiénicos y de incorporar las vacunaciones, la alimentación, las intervenciones sobre las tasas de natalidad y mortalidad, así como diversas prácticas sociales insanas (como el alcoholismo o la prostitución).

En el caso específico de lo que ocurría en ambos márgenes de la frontera argentino-brasilera, incluso con particularidades propias de cada contexto, la tendencia gubernamental oficial era la reproducción de tales prácticas, saberes y discursos que provenían de Europa y Norteamérica. La reutilización del lema mens sana in corpore sano como uno de los principales argumentos para realizar prácticas corporales -tal como aparece 
en las páginas analizadas de las publicaciones Revista do Ensino (AA.VV., 1926a; 1926b; 1926c; 1926d) y Revista de Educación (Bianchi, 1925; Shaw, 1927; Senet, 1931) - es una clara muestra de la utilización política de este razonamiento: si tradicionalmente se subordina la escolarización del cuerpo a la del intelecto, desde la década de 1920 en adelante tanto la mens como el corpore pasan a subsumirse a los discursos de lo "sano". De esta manera, educar los cuerpos significó no solamente fortalecer los músculos -es decir, modos de hacer-, sino también transmitir conductas - esto es, hábitos morales, de higiene o de carácter, teñidos de científicos, modos de ser-, terreno sobre el cual se apoyan los argumentos que permiten su asociación con los discursos eugenésicos.

Por su parte, las prácticas y discursos patrióticos resultan significativos, porque en una época en la que en Argentina y en Brasil reemerge el autoritarismo - con sus formas verticalistas de gobierno-, las intervenciones sobre los cuerpos justifican un sentido que se vuelve carne en el campo de la cultura física: la máxima de que hacer ejercicios físicos es tanto beneficio individual cuanto progreso colectivo. Esto debe comprenderse en los mencionados contextos de pasaje de la República Velha al Estado Novo en Brasil y de comienzo de la denominada Década infame en Argentina, procesos en los que el gobierno expone discursos filototalitarios que promulgan sentidos concretos políticos y éticos mediante retóricas patrióticas chauvinistas y morales conservadoras. Más aún si a ello se le suma la conformación del pensamiento que engarza la práctica deportiva como modo de representatividad de la patria, como en el caso de las competencias internacionales, que no por casualidad encuentran en este período un auge que se exponencializa, primero por su legitimación social, y luego por su masificación y universalización. En otras palabras, entre los procesos de deportivización que se producen en paralelo con la trayectoria de la civilización, tal como señalan Norbert Elias y Eric Dunning (1992), y los sucesos posteriores a la Primera Guerra Mundial, que en la mayoría de los países europeos y norteamericanos avanzaron hacia diferentes formas de totalitarismos, se encuentra la clave para entender al cuerpo moderno como efecto y representatividad de políticas públicas gubernamentales que corren el eje del organismo biológico individual hacia la colectivización de los "cuerpos correctos" -saludables, objetos de la ciencia, fuertes, viriles, disciplinados- (Vigarello, 2001; Vigarello, Corbin y Courtine, 2005).

Es sólo mediante este telón de fondo que puede entenderse el vínculo indisociable que se establece entre educación de los cuerpos y los discursos eugenésicos. Estas retóricas justificadoras de la educación de los cuerpos - por la salud y por la patria-, amparadas recurrentemente en un cientificismo monolítico, habilitaron para que la Educación Física "persiga el mejoramiento de la raza"6.

\section{ECLECTICISMO, LO TRADICIONAL Y LO MODERNO EN REVISTA}

Aun con las particularidades y recurrencias de cada contexto, aun con el recorte "pedagógico" para pensar la argentinidad y la brasilidade, el análisis de la Revista do Ensino mineira y de la Revista de Educación bonaerense permite observar una serie de estrategias editoriales comunes utilizadas para abordar temáticas atinentes a los movimientos, los cuerpos, la cultura física y sus contenidos, confrontadas con las retóricas que promueven fortalecer los músculos para mejorar la raza. Vale aclarar que, si bien es posible trazar puentes entre ambas publicaciones, lo cierto es que cada una de ellas presenta particularidades, no sólo contextuales sino también respecto a las políticas pedagógicas.

Ahora bien, puede establecerse como primera consideración cruzada, que ninguna de las dos publicaciones tuvo líneas editoriales estrictamente homogéneas en su interior, ni explicitaron un modo único y unívoco de desarrollar la educación, sino que, por el contrario, el eclecticismo fue la norma. Sin embargo, aunque no tuvieron una intencionalidad de uniformar, sí presentaron una clara intención editorial de informar y formar profesionales que siguieran estrictamente criterios científico-pedagógicos "legitimados", métodos teóricometodológicos didácticos "oficializados", y que supieran las reglamentaciones y legislaciones "superiores", respetando las modernas maneras educacionales. 
De allí que ya en sus primeras páginas la Revista do Ensino, por caso, fije como línea editorial la intención orientar, estimular e informar acerca de los asuntos pedagógicos tanto a los funcionarios educativos como a cualquier particular interesado (AA.VV., 1925, p. 1). En efecto, bajo coordinación de la Diretoria da Instrução Publica estadual de Minas Gerais, este periódico educativo se propuso publicar mensualmente, por un lado, artículos "doctrinarios" destinados a poner a los lectores al corriente de la evolución de la enseñanza primaria en todos sus aspectos, y a comunicar los direccionamientos gubernamentales que se tomen con el explícito objetivo de armonizar sus esfuerzos-, y, por el otro, noticias pedagógicas con estadísticas relativas a la educación, y sobre hechos nacionales y extranjeros -principalmente textos franceses traducidos y norteamericanos que seguían la línea pedagógica escolanovista (Vago, 2006, p. 107)-. De modo semejante, la Revista de Educación de la provincia de Buenos Aires pretendió colocarse como una publicación que a la vez tuviera una finalidad formativa y comunicativa, que contemplara las heterogeneidades pedagógicas contemporáneas, pero sin perder su rol de centralizadora. Cabe mencionar la voluntad de quienes dirigían la Revista de Educación para que sus párrafos no se agotaran en lo estrictamente escolar bonaerense y continuaran siendo una voz autorizada en materia pedagógica de formación de cierta "argentinidad", tal como lo refleja el editorial de Manuel Trigo Viera del primer número de 1924, en el cual, además de anunciar el aumento el tiraje a 5.000 ejemplares, establece que se la distribuya "entre todo el personal directivo y docente de nuestras escuelas públicas, a asociaciones, círculos, instituciones culturales y científicas, a las revistas similares del país y del extranjero, a los educacionistas y estudiosos, etc." (Trigo Viera, 1924).

En otras palabras, aun cuando no todas las notas iban en la misma dirección, y teniendo en cuenta las múltiples interpretaciones de los docentes que impartían las clases, ambas revistas se propusieron funcionar estratégicamente como dispositivos gubernamentales unificadores de sentidos, que garantizaran la difusión de la voz oficial y promovieran la reproducción de sentidos oficialmente legitimados. De allí que se afirme como característica primera el eclecticismo, que por un lado autorizaba posicionamientos diversos e incluso contradictorios, pero por otro acallaba sentidos, al no darles voz.

De hecho, aun con divergencias, lo que primaba era una heterogeneidad con tono homogeneizador: a fin de cuentas, todos los discursos publicados debían responder a los sentidos legitimados, lo cual refleja que el interés editorial estaba puesto más en el fondo de lo que se quería transmitir que en la forma. Efecto de ello, la "oficialidad" que representaban ambas revistas -que no en todos los casos era necesariamente estatal, pero sí centralizada- en muchas ocasiones cooptó sentidos publicando notas que simplificaban discusiones.

Como un síntoma de ello puede señalarse que resulta llamativa la todavía constante indefinición del nombre de la asignatura escolar que tiene por objeto explícito la pedagogía de los cuerpos. Esta discusión acerca del nombre, que parecía saldada desde la primera década del siglo XX en Argentina y en Brasil, continúa apareciendo en reiteradas notas publicadas en la Revista do Ensino y en la Revista de Educación. En efecto, aun cuando estaba aceptada la retórica casi universal de denominar Educación Física a la institucionalización del cuerpo y del movimiento, aparece constantemente una serie de términos que funcionan corrientemente como sinónimos: ejercicios físicos, gimnasia, gimnástica, calistenia, cultura física, entre otros. Todos ellos conforman el conjunto de maneras de llamar a este espacio curricular ${ }^{7}$.

Sin embargo, aun cuando pervive cierta indefinición respecto al nombre de la disciplina escolar encargada de la educación de los cuerpos, continúa reafirmándose en cada artículo publicado su importancia como parte de la grilla curricular. Particularmente se utilizan como retóricas justificadoras y legitimadoras las características de "pedagógica", "científica" y "escolar", hecho que a su vez se argumenta a partir de la complementariedad que supone educar "lo físico" respecto a "lo intelectual" y "lo moral", lo que mantiene claramente la herencia de la triada spenceriana, que es el discurso sobre el cual se constituyeron los sistemas educativos argentinos y brasileros (Galak, 2016).

Además de esta forma de construir una identidad disciplinar por reafirmación, existió una voluntad identitaria por negación: tal como puede observarse corrientemente en los párrafos editados por las revistas analizadas, la cultura física no es estrictamente militarista, no es sólo recreación y divertimento, no es 
simplemente procurar el fortalecimiento muscular y no es únicamente la espectacularización de los deportes. En todo caso, aun con la heterogeneidad de posicionamientos publicados, puede afirmarse que ambas revistas entienden la educación física como el conjunto de manifestaciones culturales legitimadas sobre los movimientos, argumentadas pedagógica y científicamente según criterios políticos.

Más allá del eclecticismo característico de la Revista do Ensino y de la Revista de Educación al publicar sentidos concretos con argumentaciones a veces contradictorias, no hay objeciones a pensar la educación de los cuerpos como vehículo o colaborador del "mejoramiento científico de la raza", sino todo lo contrario ${ }^{8}$. En efecto, una de las principales razones para ejercitarse -a saber, el sentido higiénico de la Educación Física- se transformó rápidamente en sinónimo de eugenésico. Vale aclarar que en la mayoría de los casos las notas sobre educación de los cuerpos no explicitaban seguir el ideario eugenésico, y, salvo contadas ocasiones, ni siquiera nombraban este movimiento político-científico-filosófico. Sin embargo, la retórica de que el fortalecimiento muscular deviene en mejoramiento de la raza, la incorporación de argumentaciones psicopedagógicas para administrar fichas escolares-biotipológicas clasificadoras y la utilización de discursos de eugenistas reconocidos para argumentar las prácticas disciplinares demuestran la pregnancia que tuvo el pensamiento eugenésico en los párrafos dedicados a la cultura física. Esto constituye un punto importante para observar la trascendencia que tuvieron los discursos eugenésicos en el campo pedagógico, los cuales no sólo demuestran que no fueron un bloque único monolítico, sino que resultaron al mismo tiempo un movimiento político-filosófico y una retórica en boga. La misma era utilizada en el ámbito educativo sin compromiso intencional, algunas veces "inocentemente", otras con una clara ideología en su trasfondo, pero siempre amparada en que "educar implica progresar, perfeccionar, mejorar".

Además de habilitar la posibilidad de que las notas sobre educación de los cuerpos publicadas tuvieran un carácter ecléctico, esta cuestión pone de manifiesto una retórica que se hace presente constantemente en el período estudiado: la idea de que mediante la enseñanza se progresa fue una de las principales consignas políticas pedagógicas desarrolladas en el pasaje de la Republica Velha al Estado Novo en Brasil, y por el ideario de la Década infame en Argentina (Shaw, 1927; AA.VV. 1929a; 1929b; Cometto, 1932; Penna, 1933; Mansur, 1934; Casco, 1940). Precisamente por este movimiento es que puede entenderse la corriente asociación de educar como modo de hacer progresar, mejorar o perfeccionar la raza, el colectivo, la patria.

A partir de ello puede comprenderse la habitual referencia en las notas sobre cultura física a "lo tradicional" y "lo moderno". Aparece comúnmente en las revistas una intencionalidad pedagógica por valorizar "lo tradicional" de la cultura, pero con la pretensión de resignificar lo antiguo para proyectar el futuro: en efecto, no resulta casual que ambos países atravesaran durante las décadas de 1920 y 1930 por instancias discursivas que llamaban a "refundar" el país, a crear un homem novo para un Estado Novo. En este sentido, retóricas como "científico" o "progreso" se fundieron en sinónimos de "moderno", y se constituyó acríticamente "lo moderno" como paradigma político-educativo. En otras palabras, se proponía un retorno a "lo tradicional" -sin determinar con detalle cómo se construyó- pero justificado por "lo moderno". Esta característica de los discursos escolarizados se articuló significativamente con las retóricas cientificistas de mejoramiento de la raza a través de la educación, ya que ambas se basan en una análoga cuestión temporal: precisan de una argumentación definida del ayer y de una proyección políticamente construida del mañana para operar sobre el hoy.

\section{Ser fuerte para ser útil}

La característica que aparece en ambas publicaciones pedagógicas, de hacer confluir "lo tradicional" con "lo moderno", se amparaba en retóricas que habilitaron la (con)fusión de discursos pedagógicos con aquellos eugenésicos, que de igual modo ponían el eje en lo corporal y entendían la política como una intervención en el presente a partir una planificación del futuro sostenida en una resignificación del pasado. 
Ello demuestra que no es azarosa la común y coincidente utilización de la doctrina de George Hébert para educar los cuerpos a través de la gimnasia (hasta ese entonces, principal contenido de la Educación Física): tanto la Revista do Ensino como la Revista de Educación publicaron reiteradamente notas en las que se abogaba la adopción "oficial” de lo que se conoce como Método Francés de Gimnasia o Methode Naturelle.

Este sistema gimnástico, que se popularizó internacionalmente de manera vertiginosa durante las décadas de 1920 y 1930, tenía como principal argumentación para la ejercitación de los cuerpos un "retorno a la naturaleza" (Soares, 2003) ${ }^{10}$, a tono con los idearios iluministas en boga, pero, al mismo tiempo, con un claro ideal utilitarista futuro 11 . Amparados en las retóricas de "faire des etres forts" y "être fort pour être utile", los discursos del hébertisme permitieron articular ideas pedagógicas, militaristas y patrióticas con eugenésicas: en efecto, en la base del ethos de la doctrina de Hébert se encuentra la misión de "hacer seres fuertes" y la voluntad de "ser fuerte para ser útil", a partir de subsumir al individuo al colectivo, de educarlo para que se ejercite como resultado de "mandatos superiores".

La pretensión de adoptar el Método Natural creado por un militar francés estuvo fuertemente impulsada por sectores educativos que reivindicaban la transmisión de los sentidos moralistas y patrióticos que posibilita la cultura física -lo que reafirmaba indirectamente el carácter militarista de la Educación Física-, apoyados en el hecho histórico de que en ambos márgenes de la frontera argentino-brasilera se estaban viviendo períodos de gobiernos de facto. Precisamente, uno de los procesos comunes que implica la militarización de los discursos es la subordinación de lo individual al bien común, lo cual se encuentra en las bases del hébertisme y resulta una de las principales argumentaciones para utilizar el Methode Naturelle como "oficial". En este sentido, la pretensión de educar los cuerpos para que sean fuertes y útiles, para el ciudadano, para la patria y para la "raza argentina" o "brasilera", significó una de las justificaciones más corrientes para legitimar y masificar las prácticas públicas de cultura física, como las plazas de ejercicios físicos, las colonias de vacaciones, las justas deportivas centralizadas, entre otras.

En lo que respecta a la educación de los cuerpos, existe una llamativa relación histórica entre discursos eugenésicos y militaristas, la cual, aun con argumentaciones particulares y distintivas, refleja cierta imbricación que las hace parecer indisociables. Puede interpretarse que ello se debe a la corriente asociación de la eugenesia con los movimientos totalitaristas de Europa (principalmente el nazismo con sus Leyes de Núremberg y el fascismo italiano con su Manifesto della razza), los cuales permitieron legitimar y popularizar la doctrina eugenésica como científica. Sin embargo, también puede suponerse que ello era producto de que para mejorar la raza en términos más reales que simbólicos era necesaria cierta verticalidad y homogeneización, dos recursos característicos de las doctrinas militaristas.

En definitiva, la tarea individual de fortalecer los músculos se transformó en responsabilidad moral colectiva, fuera para el "crecimiento del brazo productivo" de la ("mano de obra" de la) nación, fuera como responsabilidad profiláctica, no ya solamente del organismo biológico, sino también del organismo social. Precisamente, los discursos eugenésicos se apoyan necesariamente sobre esta condición, al partir de la afirmación de que toda política para el mejoramiento científico de la raza se basa en una intervención del cuerpo colectivo de las poblaciones sobre el organismo biológico individual.

A su vez, además de este gesto típicamente moderno del período de subsumir lo individual a lo colectivo, se produjo la articulación con otro proceso análogo que se hizo explícito en ese momento: el interés de lo público por el gobierno de lo privado. De esta manera, se incorporó como efecto el régimen del autocontrol como modelo de control, hecho por el cual "lo moral" - política que devino en ética- pasó a ocupar un lugar preponderante en la educación de "lo físico". En última instancia, por las dudas de que el autocontrol fallase, el poder punitivo y la policía como brazo armado legitimado del Estado, en pleno auge durante las décadas de 1920 y 1930, se encargaron de "recordar" a los infractores sus responsabilidades. 


\section{Institucionalizar la palabra}

Una cuestión importante a señalar es la estrategia editorial común de la Revista de Educación y de la Revista do Ensino respecto del peso otorgado a la institucionalización, la cual es otra característica de la época (que en parte está articulada con la mencionada sumisión de lo individual a lo colectivo y con el gobierno público de lo privado). En este sentido, los procesos de institucionalización por los que atravesaron las prácticas pedagógicas en aquellos años resultaron ser al mismo tiempo un punto de partida, así como un horizonte político: su legitimación se basó en la racionalidad y sistematicidad de la organización institucionalizada, que no siempre en su fondo era producto del Estado, pero que se apoyaba en las formas del brazo estatal centralizado. Dicho de otra manera: si los procesos de institucionalización son constitutivos de la modernidad -o de lo que podría denominarse como una experiencia trasnacional y transgeneracional compartida, en absoluto universal pero sí universalizante, que encuentra en los grandes relatos sociales, como la familia, la Iglesia o el Estado, la manera de expresar sus términos-, las décadas de 1920 y 1930 radicalizan esta condición al reconfigurar la institucionalización como modo político legitimado y dominante.

Por caso, los procesos de escolarización como modo institucionalizado y legítimo de transmitir maneras de ver, hacer, decir y sentir son un claro ejemplo de esta característica de la época. De hecho, puede esbozarse que el crecimiento exponencial de la institucionalización como modo cultural socialmente reconocido de organización, que se profundiza en la segunda década del siglo XX, reemplazó al sueño comeniano de materializar la universalización de la escolaridad para enseñarle todo a todos al mismo tiempo y amplió sus alcances: de allí que pueda observarse una coincidencia editorial entre ambas publicaciones al interpretar que los procesos de escolarización traspasan los muros de las escuelas.

Por otro lado, la importancia que se le otorga a la institucionalización explica el porqué del constante uso de la Revista do Ensino y de la Revista de Educación como tribuna política para desarrollar centralizadamente la formación de profesionales encargados de la educación de los cuerpos (AA.VV., 1924; AA.VV., 1929a; Koeler y Pinto, 1930; Iglesias, 1937; Arizaga, 1938; Romero Brest, 1938). De hecho, si bien ambas publicaciones tenían como mandato fundacional el objetivo de actualizar constantemente a los docentes a partir de la retórica de "modernizar" los discursos, durante las década de 1920 y 1930 son recurrentes los artículos que paralelamente abogan por una institucionalización que profesionalice específicamente a educadores de los cuerpos ${ }^{12}$.

A su vez, la editorialización de ideas pedagógicas en revistas para su masificación es, en sí misma, una clara manifestación de la importancia que supusieron los modos institucionalizados durante este período: no resulta casual que en la década de 1920 sea particularmente significativa la proliferación de publicaciones como modo legitimado de divulgación de palabras y sentidos "oficiales" ${ }^{13}$. En esta dirección, el movimiento eugenésico no podría ser pensado si no es atravesado por las lógicas de la institucionalización: las asociaciones pedagógicas y psicologicistas, las ligas profilácticas, de higiene mental, de higiene social o de educación, contra la tuberculosis, el juego (jogo do bicho) o la prostitución, a favor del asistencialismo y del proteccionismo de la infancia, entre otros modos que se produjeron a ambos márgenes de la frontera argentino-brasilera (Stepan, 1991; Vallejo y Miranda, 2005; 2007), son reflejos de que los discursos acerca de la eugenesia se reprodujeron a través de diversas formas institucionalizadas. Ello explica por qué en las páginas de ambas publicaciones analizadas aparecen constantemente notas pedagógicas y circulares de organismos estatales ligados a la ciencia médica, con un fuerte apelo a la intervención de políticas públicas higienistas sobre los cuerpos. Entre otros artículos, se destaca la sección "Cuerpo Médico Escolar" para el caso de la revista bonaerense, que progresivamente ocupó un lugar central en las directivas sobre el uso de prácticas corporales para el mejoramiento de la raza; su director era Carlos Cometto, quien recurrentemente abogaba por una cultura física comandada por médicos y secundada por profesionales de la Educación Física (1922; 1925; 1932). En tanto, en la Revista do Ensino mineira sobresalen las referencias a eugenistas brasileros reconocidos, especialmente a Renato Kehl (Folk, 1926; Mansur, 1934). 


\section{Transmitir sin decir}

Por último, se establecen cuatro consideraciones finales que refieren mayoritariamente a lo que las revistas analizadas "dijeron sin decir", o que directamente acallaron.

Primero, el tratamiento compartido por parte de ambas publicaciones de lo femenino como secundario -o como mínimo-, como subespecie que requiere especificidades. En efecto, siempre que se refiere a condiciones dirigidas particularmente a las mujeres se lo explicita: de allí que aparezcan notas sobre "cultura física femenina", "deportes para las mujeres", entre otras. Esta perspectiva sigue reproduciendo el histórico ideario que asume que el cuerpo de las mujeres es débil, aunque en este período se destaca que, a diferencia de tiempos finiseculares en los que directamente se desaconsejaba, e incluso se prohibía, cualquier tipo de ejercitación física para las mujeres, esa "debilidad" pareciera ser interpretada en algunos casos como "enfermedad", y que, por ello, debe ser intervenida. De hecho, sobresalen las notas sobre la importancia de la ejercitación y cuidado de la zona pélvica o las referencias al sexo femenino como "laboratorio de las generaciones futuras" (Folk, 1926, p. 330), lo cual explica por qué las recomendaciones editoriales de la Revista de Educación y de la Revista do Ensino para que las mujeres practiquen gimnasias "blandas" o deportes sin contacto físico directo.

Segundo, tal como se esbozó previamente, se produce la definitiva legitimación social de los deportes como potencial contenido escolar, al mismo tiempo que comienza a perfilarse como principal recurso pedagógico de la Educación Física en detrimento de las gimnasias. Si bien se da esta situación -y sin dejar de lado el hecho de que crece exponencialmente el número de artículos al respecto-, no desparecen definitivamente las voces pedagógicas que continúan en contra de la incorporación de los deportes a las escuelas. De hecho, si se tiene en cuenta la masificación deportiva que ocurre en el segundo cuarto del siglo XX, y la amplia difusión que se daba en otros carriles comunicativos, es llamativa la poca cantidad de líneas dedicadas a los deportes, lo cual permite esbozar que las lógicas editoriales de la Revista do Ensino y de la Revista de Educación fueron reticentes a aceptar (y publicar) abiertamente notas que difundieran la idea de que los deportes podrían funcionar como recurso pedagógico.

Tercero, que si bien las décadas de 1920 y 1930 resultaron particularmente significativas para desarrollar discursos patrióticos que atravesaron los circuitos educativos, que exaltaban lo nacional por momentos de un modo filochauvinista, se utilizaron para ello retóricas importadas del extranjero, particularmente norteamericanas y europeas. En efecto, se produce la paradoja de reafirmar lo propio y lo interno a partir de resignificar argumentaciones ajenas construidas en el exterior.

Por último, que si bien la idea de "raza” aparece comúnmente en las publicaciones de la Revista do Ensino y en la Revista de Educación, no son tan corrientes las especificaciones de lo que significa esa "raza". De hecho, quizás esta cuarta cuestión pueda ser explicada en parte por la tercera, gracias a la importación de retóricas (en boga) raciales principalmente de Europa y de los Estados Unidos. Sin embargo, resulta importante destacar que no aparecen referencias de relieve respecto al mestizaje, a la hibridez o a la extranjerización, cuestiones que en otros ámbitos - como el de la prensa estrictamente eugenésica (Vallejo y Miranda, 2005; 2007; 2012)estaban comenzando a discutirse con cierta insistencia. Tanto el acento en la "españolidad" y en el desdén por lo gauchesco o aborigen de la "raza argentina" -como el destaque de las raíces imperiales portuguesas y la minimización del negro y el mulato de la "raza brasilera" - son claros ejemplos de que la cuestión estaba implícitamente presente en las revistas pero incipientemente tematizada, incluso cuando su discusión estaba ya instalada en ambos márgenes de la frontera argentino-brasilera. 


\section{A MODO DE CIERRE}

Los análisis de la Revista do Ensino y de la Revista de Educación demuestran la constancia y significatividad de las políticas sobre educación eugenésica de los cuerpos durante las décadas de 1920 y 1940, a ambos márgenes de la frontera argentino-brasilera.

Puede aventurarse que las consideraciones realizadas, si bien emergen de la reflexión específica de dos revistas pedagógicas estaduales oficiales, no son exclusivas de éstas: efectivamente, trascienden estas publicaciones, y se pueden encontrar algunos rasgos similares en épocas anteriores y posteriores. De hecho, puede afirmarse que los saberes, prácticas y discursos sobre el mejoramiento racial que se desarrollaron en Argentina y Brasil durante el período indagado, si bien emparentables, no resultaron comparativamente iguales ni homogéneos en su interior. Por ello, es pertinente, antes que referir a una argentinidad o brasilidade en singular, pensar en las conformaciones de "regímenes" en plural: "regímenes de argentinidad” y "regímenes de brasilidade". Del ejercicio de confrontar tales procesos, pero fundamentalmente a partir de interpelar sus particularidades y recurrencias históricas, es posible desnaturalizar el devenir histórico y afirmar la operación del cuerpo como objeto de políticas públicas, eugenésicas y educativas.

En efecto, el ideario que indica educar los cuerpos para mejorar la raza marca un clima de época que mantiene sentidos tradicionales del campo de la cultura física, como también sus características de argumentarse eclécticamente, de considerarse pragmática y pedagógica, de fundamentarse como eminentemente científica y promotora de hábitos higiénicos. Pero también los resignifica: el cientificismo como retórica legitimadora ubica a los discursos sobre educación de los cuerpos en un lugar central de las políticas gubernamentales, significándolos como "oficiales" e invistiéndolos de una particular interpretación de moderno. En síntesis, estos sentidos de la episteme disciplinar son distintivos en Argentina y en Brasil, aunque también se reproducen con matices en la mayoría de los contextos occidentales, cuyas principales características asociadas a "lo tradicional" y a "lo moderno" perviven hasta la actualidad.

De este modo, pueden observarse los discursos que transmitieron la revista bonaerense y la revista mineira acerca de la cultura física como vehículo para reproducir retóricas eugenésicas y, con ello, puede comprenderse qué sentidos sobre cientificismo, salubridad y patriotismo se publicaron, entendidos éstos como sinónimos de progreso y de civilidad. En esta dirección puede observarse que para esas líneas editoriales la enseñanza de prácticas corporales sirve para, es decir, la misma porta una clara intención utilitariopragmática, especialmente destinada a subsumir el cuerpo individual a los cuerpos colectivos, y, con ello, confundir el fortalecimiento de los músculos con el progreso de la patria y el perfeccionamiento de la raza. De allí que las significaciones dominantes sobre cultura física se destinaron a la formación de subjetividades a través de la educación de los cuerpos; de allí que, en definitiva, la Revista de Educación y la Revista do Ensino transmitieron tanto modos de hacer como modos de ser "correctos".

Ahora bien, resulta importante para futuras indagaciones dejar planteada una serie de preguntas para continuar interpelando no sólo con lo que se publicó en las revistas pedagógicas, sino también para interpretar las razones por las que temáticas que estaban presentes en las políticas públicas educativas de ambos países no se vieron simétricamente reflejadas en sus páginas. En este sentido, ¿qué grados de sintonía pueden hallarse en la traducción de idearios eugenésicos transnacionales (especialmente europeos y norteamericanos) a los contextos argentino y brasilero? ¿Pueden pensarse características estrictamente particulares de la educación eugenésica de los cuerpos en Brasil y Argentina? De modo semejante, la introducción de los discursos médicoeugenésicos a los contextos educativos, ¿supuso una resignificación de sentidos? Un interesante modo de continuar esta indagación es la comparación entre lo que las instituciones eugenésicas y los principales autores eugenistas planteaban por aquellos años como educativo, y, a su vez, lo que los órganos estatales de escolarización propusieron para "hacer seres fuertes" y también respecto al objetivo de "ser fuerte para ser útil". 
A su vez, en relación con ello, ¿qué vínculos pueden establecerse entre las notas publicadas en la Revista de Educación y en la Revista do Ensino con las políticas públicas estatales desarrolladas en Buenos Aires y Minas Gerais respectivamente? ¿Qué grado de homogeneización puede identificarse en los regímenes de argentinidad y de brasilidade? Como pudo observarse en el análisis realizado, incluso cuando ambas eran "oficiales", no siempre las líneas editoriales y las políticas educativas gubernamentales estuvieron íntimamente relacionadas. Esto se ve claramente en la insistente consideración de las revistas acerca de profesionalizar el campo de la cultura física -cuestión que no se vio reflejada de igual modo en las políticas públicas o en el uso editorial de las retóricas eugenésicas- sin apelar a una intervención médica para el mejoramiento de las razas, al estilo de lo que ocurría simultáneamente en Europa y Estados Unidos. A sabiendas de que no existió una relación directa entre estos dos modos de "oficialidades", es importante marcar las tensiones entre las "retóricas de lo oficial" que se produjeron en el interior de cada contexto, ya que eso permite comprender no sólo que los discursos dominantes no fueron monolíticos, sino fundamentalmente que en los intersticios de lo que se entiende como verdadero se esconden los sentidos que llevan a interpretar "lo que viene siendo" como "lo que debe ser".

$\mathrm{Si}$, como sostiene Marx, la naturalización es el olvido de toda historia, y si como afirmó Michel Foucault, interesa más pensar la historia de nuestras verdades que la verdad de nuestra historia, entonces vale la pena reflexionar sobre los sentidos históricos dominantes que se materializaron en políticas públicas, ya que esto posibilita comprender los efectos del cientificismo y de la medicalización de la vida, que condicionan los modos legitimados de producción de cuerpos. En este sentido, la educación sería a la vez el principal mecanismo tanto para su reproducción como para la producción de prácticas emancipatorias.

\section{REFERENCIAS}

AA.VV. (1924). A propósito de educación física. La Escuela Normal de Educación Física de La Plata. Revista de Educación de la provincia de Buenos Aires, 65(4), 960-963.

AA.VV. (1925). Editorial. Revista do Ensino, 1(1), 1-2.

AA.VV. (1926a). Para fazer uma raça forte e enérgica. Methodos de Educação Physica. Revista do Ensino, 2(10), 29-31.

AA.VV. (1926b). Para fazer uma raça forte e enérgica. Methodos de Educação Physica. Revista do Ensino, 2(11), 60-61.

AA.VV. (1926c). Para fazer uma raça forte e enérgica - Andar na ponta dos pés. Revista do Ensino, 2(12), 104.

AA.VV. (1926d). Educação Physica. A gymnastica torna o corpo sadio, bello e forte, sugerindo ao espirito força da vontade, energia, coragem, decisão, alegria e cordialidade. Revista do Ensino, 2(18), 387-389.

AA.VV. (1929a). Educação Physica (Instruções baixadas pela Inspetoria Geral da Instrução). Revista do Ensino, 4(32), 73-75.

AA.VV. (1929b). Scoutismo, escuela y hogar. Revista de Educación de la provincia de Buenos Aires, 70(10), 418-420.

Aguirre, R. (1923). Higiene escolar. Revista de Educación de la provincia de Buenos Aires, 64(1), 118-121.

Aisenstein, Á., y Scharagrodsky, P. (2006). Tras las huellas de la Educación Física Escolar Argentina. Cuerpo, género y pedagogía. 1880-1950. Buenos Aires: Prometeo.

Arizaga, J. (1938). Balance de los cursos de perfeccionamiento. Revista de Educación de la provincia de Buenos Aires, 79(2), 35-43.

Bianchi, R. (1925). Los problemas de la educación moderna. A propósito de la gimnasia escolar. Revista de Educación de la provincia de Buenos Aires, 66(1), 29-32.

Bisso, A. (2011). La Revista Educación bonaerense durante el período de gobierno de Manuel A. Fresco (1936-1940): acerca de los "usos del pasado" en los discursos y las prácticas escolares. Clío y Asociados, 15, 27-52.

Bourdieu, P. (2014). Sobre el Estado. Buenos Aires: Anagrama. 
Casco, E. (1940). La Educación Física como medio para aplicar las leyes de honor. Los «clubs» de niños. El «scoutismo». La música como medio de atracción en la escuela. El canto coral. Revista de Educación de la provincia de Buenos Aires, 81(5), 29-36.

Castro-Gómez, S., y Restrepo, E. (2008). Genealogias de la colombianidad. Formaciones discursivas y tecnologias de gobierno en los siglos XIX y XX. Bogotá: Pensar.

Cometto, C. (1922). La Visitadora Escolar. Necesidad de crear un servicio de visitadoras escolares en las principales ciudades de la provincia. Revista de Educación de la provincia de Buenos Aires, 63(7), 792-800.

Cometto, C. (1925). El beso entre niñas. Costumbre que debe combatirse desde la escuela. Revista de Educación de la provincia de Buenos Aires, 66(3), 662-664.

Cometto, C. (1932). Ficha sanitaria escolar. Revista de Educación de la provincia de Buenos Aires, 73(2), 283.

Elias, N., y Dunning, E. (1992). Deporte y ocio en el proceso de la civilización. Madrid: Fondo de Cultura Económica.

Espósito, R. (2007). Bios: biopolitica y filosofía. Buenos Aires: Amorrortu Editores.

Folk (1926). Pela beleza da raça. Números de gymnastica rythmica praticada por alunas dos nossos grupos escolares, Revista do Ensino, 2(16), 329-330.

Foucault, M. (1996). Genealogía del racismo. La Plata: Altamira.

Galak, E. (2009). El cuerpo de las prácticas corporales. En R. Crisorio (comp.), Educación Física. Estudios Críticos en Educación Fisica (pp. 271-284). La Plata: Al Margen.

Galak, E. (2014a). Raça. En F. González y P. Fensterseifer [orgs], Dicionário crítico de Educação Física. 3a Edição Revisada e Ampliada (pp. 558-562). Ijuí: Editora Unijuí.

Galak, E. (2014b). Educación del cuerpo y política. Concepciones de raza, higienismo y eugenesia en la Educación Física argentina. Revista Movimento, 20(4), 1543-1562.

Galak, E. (2015a). 'A educação física busca o aperfeiçoamento da raça': políticas públicas, saúde, eugenia e educação dos corpos. En Y. Carvalho, A. Branco Fraga y I. Gomes [orgs], Práticas corporais no campo da saúde (pp. 47-74). Porto Alegre: Rede Unida Editores.

Galak, E. (2015b). Una historia en fragmentos: los orígenes de la institucionalización de la 'educación de los cuerpos bonaerenses' (1910-1940). En E. Galak y E. Gambarotta (comp.), Cuerpo, educación, politica: tensiones epistémicas, históricas y prácticas (pp. 101-126). Buenos Aires: Biblos.

Galak, E. (2016). Educar los cuerpos al servicio de la politica. Cultura física, higienismo, raza y eugenesia en Argentina y Brasil. Buenos Aires: Biblos.

Goís, E., y Lovisolo, H. (2005). A educação física e concepções higienistas sobre raça: uma reinterpretação histórica da educação física brasileira dos anos de 1930. Revista Portuguesa de Ciências do Desporto, 5(3), 322-328.

Gomes, L. (1925). A Eugenia. Revista do Ensino, 1(1), 29-30.

Iglesias, E. (1937). Necesidad de instruir una doctrina educativa. La reforma escolar bonaerense. Revista de Educación de la provincia de Buenos Aires, 78(2), 28-36.

Kinoshita, C., Pimenta Rocha, H., y Aisenstein, A. (2015). Circulação de ideias eugênicas entre Brasil e Argentina: os contatos de Renato Kehl com Victor Delfino e Alfredo Verano. En H. Pimenta Rocha y M. Borges Salvadori (ed.), Entre Brasil e Argentina: miradas sobre a história da educação (pp. 83-119). Belo Horizonte: Fino Traço.

Koeler, E., y Pinto, N. (1930). Qual a parte deve caber á educação physica no ensino primário. Revista do Ensino, 5(47).

Mansur, S. F. (1934). Importância dos exercícios physicos, Revista do Ensino, 8(107), 45 -47.

Miranda, M., y Girón Sierra, A. (2009). Cuerpo, biopolitica y control social. América Latina y Europa en los siglos XIX $y X X$. Buenos Aires: Siglo XXI.

Morzone, L. (1927). El trabajo manual en las escuelas. Revista de Educación de la provincia de Buenos Aires, 68(2), 334-384.

Penna, M. (1933). A ginastica do trabalho. Revista do Ensino, 7(92), 20-21.

Pineau, P., Dussel, I. y Carusso, M. (2001). La escuela como máquina de educar. Buenos Aires: Paidós. 
Romero Brest, E. C. (1938). Aplicación a la Educación Física del niño. Revista de Educación de la provincia de Buenos Aires, 79(4), 110-114.

Senet, R. (1931). La Educación Integral (Fragmento de una obra en prensa). Revista de Educación de la provincia de Buenos Aires, 72(2), 314-399.

Shaw, E. (1927). El juego fortalece a los niños. Revista de Educación de la provincia de Buenos Aires, 73(1), $43-47$.

Scharagrodsky, P. (2011). La invención del "homo gymnasticus". Fragmentos históricos sobre la educación de los cuerpos en movimiento en Occidente. Buenos Aires: Prometeo.

Scharagrodsky, P. (2014). Miradas médicas sobre la cultura física en Argentina: 1880-1970. Buenos Aires: Prometeo.

Soares, C. (2003). Georges Hébert e o Método Natural: nova sensibilidade, nova educação do corpo. Revista Brasilera de Ciências do Esporte, 25(1), 21-39.

Soto, P. (hijo). (1926) La cultura física. Revista de Educación de la provincia de Buenos Aires, 67(2), 433-435.

Stepan, N. (1991). The hour of eugenics: race, gender and nation in Latin America. New York: Cornell University Press.

Strohl, D. (1937). Un método de Educación Física para la juventud. Revista de Educación de la provincia de Buenos Aires, 78(2), 67-72.

Trigo Viera, M. (1924). La «Revista de Educación» en 1924. Revista de Educación de la provincia de Buenos Aires, 65(1), 5-12.

Vago, T. (2004). Da ortopedia à eficiência dos corpos: a gymnastica e as exigências da 'vida moderna' (Minas Gerais, 1906-1930). Revista Movimento, 10(3), 77-97.

Vago, T. (2006). Educação física na Revista do Ensino de Minas Gerais (1925-1935). Organizar o ensino, formar o professorado. Revista Brasileira de História da Educação, 11, 101-134.

Vallejo, G., y Miranda, M. (2005). Darwinismo social y eugenesia en el mundo latino. Buenos Aires: Siglo XXI.

Vallejo, G., y Miranda, M. (2007). Politicas del cuerpo. Estrategias modernas de normalización del individuo y la sociedad. Buenos Aires: Siglo XXI.

Vallejo, G., y Miranda, M. (2012). Una historia de la eugenesia: Argentina y las redes biopoliticas internacionales. Buenos Aires: Biblos.

Veiga, C., y Fonseca, Th. (2003). História e historiografia da educação no Brasil. Belo Horizonte: Autêntica.

Veiga, C. (2007). História da Educação. São Paulo: Editora Ática.

Vigarello, G. (2001). Corregir el cuerpo. Historia de un poder pedagógico. Buenos Aires: Nueva Visión.

Vigarello, G., Corbin, A., y Courtine, J. (2005). Historia del cuerpo. Madrid: Taurus.

\section{Notas}

1 Ésta fue la temática que se analizó en la investigación de posdoctorado titulada “'Cuerpo', 'sujeto' y 'política' en la educación de los cuerpos argentina y brasilera: eugenesia y Educación Física entre las décadas de 1920 y 1930", financiada por la Coordenação de Aperfeiçoamento de Pessoal de Nivel Superior (CAPES, Brasil) y radicada en la Universidade Federal de Minas Gerais (UFMG, Brasil), entre 2013 y 2014. En este escrito se presentan las principales consideraciones construidas, con la aclaración de que por cuestiones de formato se recortó la exposición de las fuentes en favor de un análisis teórico de las mismas. La principal razón de ello se debe a que las fuentes representan un material cuantioso, habida cuenta de que la Revista do Ensino y Revista de Educación fueron publicadas ininterrumpidamente con un promedio de dos números por mes en el lapso de las dos décadas que abarca el recorte temporal-. Para observar un detallado análisis de las fuentes se invita a la lectura de (Galak, 2016).

2 Estas cuestiones son trabajadas conceptualmente (Galak, 2014a) y en (Galak, 2014b).

3 Acerca de la relación entre el contexto macro político internacional, las coyunturas gubernamentales en Argentina y en Brasil en el segundo cuarto del siglo XX y los discursos de educación eugenésica de los cuerpos se recomienda especialmente la lectura de los trabajos de Nancy Stepan (1991), Gustavo Vallejo y Marisa Miranda (2005; 2007; 2012) y de Carolina Kinoshita, Heloísa Rocha Pimenta y Ángela Aisenstein (2015). 
4 En este punto se extiende la tesis de Santiago Castro-Gómez y Eduardo Restrepo acerca de la imposibilidad de comprender de manera singular y homogénea la nacionalidad -en su caso referida a la colombianidad-, sino que, por el contrario, debe entenderse en plural, como campos de disputas entre distintas posiciones históricas (2008, p. 11).

5 Si bien no son numerosos los estudios que indaguen la relación entre discursos sobre mejoramiento de la raza en Argentina y en Brasil, es posible afirmar que esta investigación se basa en los precursores trabajos de Nancy Stepan (1991), Gustavo Vallejo y Marisa Miranda (2005; 2007; 2012) y de Marisa Miranda y Álvaro Girón Sierra (2009). A su vez, especialmente referidos a la educación eugenésica de los cuerpos esta indagación se sustenta en las consideraciones que al respecto esbozaron Edivaldo Goís Junior y Hugo Lovisolo (2005), Pablo Scharagrodsky -tanto sus compilaciones “La invención del 'homo gymnasticus'. Fragmentos históricos sobre la educación de los cuerpos en movimiento en Occidente" (2011) y “Miradas médicas sobre la cultura física en Argentina: 1880-1970" (2014) como el libro que realiza con Ángela Aisenstein (2006) - y Carolina Kinoshita, Heloísa Pimenta Rocha y Ángela Aisenstein (2015).

6 Precisamente, esto puede verse esbozado en (Galak, 2015a)

7 Esta multiplicidad y convivencia de sentidos puede ser observada en las fuentes primarias (Bianchi, 1925; AA.VV., 1926b; Soto, 1926; AA.VV., 1929b; Penna, 1933; Mansur, 1934; Strohl, 1937; Romero Brest, 1938; Casco, 1940). Resulta importante señalar en este conjunto de referencias la presencia de notas de David Strohl, discípulo del inventor del método natural francés Georges Hébert, y de Enrique Carlos Romero Brest, el hijo del "padre de la Educación Física” argentina (Scharagrodsky, Aisenstein, 2006), de larga tradición en la formación profesional disciplinar (Galak, 2016).

8 Como una muestra de las diversas fuentes que en la prensa pedagógica estudiada hacen referencia a sentidos higiénicoeugenésicos, pueden revisarse las siguientes fuentes primarias: "Higiene escolar" de Roberto Aguirre (1923), "A Eugenia" de Lindolpho Gomes (1925), la entrega en fascículos del artículo "Para fazer uma raça forte e enérgica. Methodos de Educação Physica” (AA.VV., 1926a; 1926b; 1926c) y los artículos que Carlos Cometto publicó en la sección "Cuerpo Médico Escolar" (1922; 1925; 1932).

9 Por caso, AA.VV., 1926d; Strohl, 1937.

10 Resulta interesante que este discurso del hébertisme refiere a cierto posicionamiento que interpreta a la gimnasia como un modo de "retorno a la naturaleza" mediante la ejercitación, dirigido a una población "iluminada", que coexistía con "otros" que aún "ni siquiera habían salido de la naturaleza". La propuesta del Méthode Naturelle es un romanticismo que a fin de cuentas refleja un problema de clases, una propuesta de "retorno a determinada naturaleza".

11 Una cuestión tangencial no menor la constituye el hecho de que, si bien históricamente la cultura física está asociada a sentidos de utilidad, durante este período analizado sobresalen las notas pedagógicas en la Revista do Ensino y la Revista de Educación en las cuales se contrapone la "gimnasia" a los "trabajos manuales" como dos modos disímiles de comprender la "utilidad" de educar los cuerpos. Incluso algunos artículos plantean su antagonismo (Penna, 1933; Morzone, 1927). En efecto, mientras que a las primeras se les adjudica la potencialidad de mejorar el rendimiento físico y producir el descanso de la mente, los segundos beneficiarían el desarrollo de aptitudes para la vida adulta del trabajador.

12 Como ejemplos paradigmáticos, pueden verse los artículos "Educação Physica (Instruções baixadas pela Inspetoria Geral da Instrução)" (AA.VV., 1929a) y “A propósito de educación física. La Escuela Normal de Educación Física de La Plata” (AA.VV., 1924). Para un análisis pormenorizado se recomienda la lectura de "Educação física na Revista do Ensino de Minas Gerais (1925-1935). Organizar o ensino, formar o professorado” para observar el caso mineiro (Vago, 2006) y "Una historia en fragmentos: los orígenes de la institucionalización de la 'educación de los cuerpos bonaerenses”" (Galak, 2015b).

13 De hecho, la Revista do Ensino es hija explícita de este proceso, tal como puede leerse en la reforma educativa de Minas Gerais impulsada por Mello Vianna en 1925, analizada por Vago (2004; 2006). 